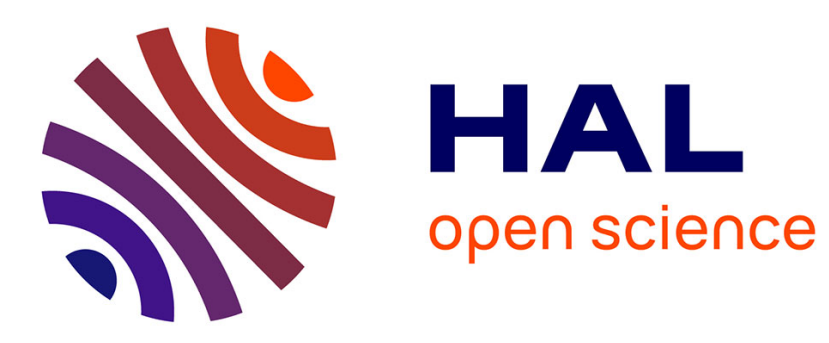

\title{
Thermal-oxidation of epoxy/amine followed by glass transition temperature changes
}

\author{
Esteve Ernault, Emmanuel Richaud, Bruno Fayolle
}

\section{To cite this version:}

Esteve Ernault, Emmanuel Richaud, Bruno Fayolle. Thermal-oxidation of epoxy/amine followed by glass transition temperature changes. Polymer Degradation and Stability, 2017, 138, pp.82-90. 10.1016/j.polymdegradstab.2017.02.013 . hal-01493877

\section{HAL Id: hal-01493877 https://hal.science/hal-01493877}

Submitted on 22 Mar 2017

HAL is a multi-disciplinary open access archive for the deposit and dissemination of scientific research documents, whether they are published or not. The documents may come from teaching and research institutions in France or abroad, or from public or private research centers.
L'archive ouverte pluridisciplinaire HAL, est destinée au dépôt et à la diffusion de documents scientifiques de niveau recherche, publiés ou non, émanant des établissements d'enseignement et de recherche français ou étrangers, des laboratoires publics ou privés. 


\title{
Thermal-oxidation of epoxy/amine followed by glass transition temperature changes
}

\author{
Esteve Ernault, Emmanuel Richaud*, Bruno Fayolle \\ PIMM UMR 8006, Arts et Métiers ParisTech, CNRS, CNAM, 151 bd de l'Hôpital, Paris, France
}

\section{A R T I C L E I N F O}

\section{Article history:}

Received 23 January 2017

Received in revised form

22 February 2017

Accepted 26 February 2017

Available online 28 February 2017

\section{Keywords:}

Epoxy/diamine

Glass transition

Chain scission

Crosslinking

\begin{abstract}
A B S T R A C T
Thermal oxidation of three epoxy resins differing by the nature of prepolymer (bisphenol A diglycidyl ether and 1,4-butanediol diglycidyl ether) and hardener (isophorone diamine and 4,7,10-Trioxa-1,13tridecanediamine) was studied by monitoring changes in glass transition temperature using DSC. Results were discussed using the DiMarzio's approach in which parameters are estimated from an additive group contribution. This theory allowed a fair assessment of $T_{g}$ values for unaged networks. During oxidation, epoxy networks were shown to undergo chain scissions occurring in great part in hydroxypropyl ether and isophorone groups. However, the exploitation of $\mathrm{T}_{\mathrm{g}}$ changes showed the coexistence and even the predominance of crosslinking in materials having linear aliphatic segments. The DiMarzio's approach was used to discuss the possibility of intramolecular cyclization or intermolecular crosslinks which were shown to predominate. Crosslinks were tentatively justified from a mechanistic point of view and quantified depending on experimental conditions.
\end{abstract}

\section{Introduction}

Since they are designed for high temperatures applications as matrix for composites, most of the epoxy networks are made of a rigid epoxy and rigid hardener (for example DGEBA/DDS or DGEBA/ DDM) [1-13]. Their degradation is very often studied by mass loss $[4,6,8,10]$ which is clearly shown:

- to be associated to the chain scission induced by decomposition of hydroperoxides $[7,8]$.

- to occur quasi instantaneously, since hydroperoxides formed in epoxy amine networks are unstable due to the vicinity of heteroatoms (see for example Table 4.15 vs Table 7.15 in Ref. [14]) which induces the short kinetic chains being an intrinsic characteristic of epoxy resins [8].

It is thus not surprising that mass losses exceeding $10 \%$ are measured during thermal ageing $[4,6,8]$ which leads to shrinkage in the oxidized superficial layer in the case of thick samples $[15,16]$.

Some studies also address the consequences of oxidation on the architecture of polymer networks. They show the depletion of glass

\footnotetext{
* Corresponding author.

E-mail address: emmanuel.richaud@ensam.eu (E. Richaud).
}

transition i.e. that rigid networks (with $\mathrm{T}_{\mathrm{g}}$ higher than $150{ }^{\circ} \mathrm{C}$ ) undergo chain scissions $[1,11,13,17]$.

This short literature review suggests the existence of a major or even exclusive chain scission process leading to the loss of mass and ultimate mechanical properties. However, those phenomena were mainly evidenced in rigid epoxy/diamine systems where 2hydroxypropyl ether is possibly the only reactive site. The case of flexible epoxies $\left(\mathrm{T}_{\mathrm{g}}<100^{\circ} \mathrm{C}\right)[18,19]$ was more scarcely studied so that we were interested in investigating:

- if the above scenario is common to all epoxy networks, or if there are some peculiarities for epoxies with aliphatic linear groups.

- if chain scissions exclusively occur or could they be counterbalanced by crosslinking events ?

- if there is an influence of external parameters (temperature, oxygen pressure) on the consequences of oxidation (at molecular scale i.e. the consequences of the formation of carbonyls or amides), and on the architecture of epoxy networks and later on its thermomechanical properties.

To answers those questions, our investigations will base on a series of epoxy/amine networks differing by their content in aliphatic sequences [20]. Their thermal degradation will be studied at several temperatures and oxygen pressures. A modeling 
approach based on DiMarzio's equation [21] will be first checked on unaged networks and then adapted for taking into account the presence of chain scissions and crosslinks. It will be used to quantify the changes at macromolecular level.

\section{Experimental}

\subsection{Materials}

Epoxy/diamine systems were synthesized using the resins and hardeners shown in Fig. 1:

- A Diglycidyl ether of bisphenol A DER 332 resin named here DGEBA (CAS 1675-54-3 - ref 31185 supplied by Sigma Aldrich) has a degree of polymerization $n$ close to 0 and a number average molecular mass equal to $340 \mathrm{~g} \mathrm{~mol}^{-1}$.

- A Diglycidyl ether of 1,4-butanediol resin named here DGEBU (CAS 2425-79-8 ref 220892 supplied by Sigma Aldrich, $\mathrm{M}=202.25 \mathrm{~g} \mathrm{~mol}^{-1}$ ).

- An isophorone diamine hardener named here IPDA (CAS 285513-2 - ref 118184 supplied by Sigma Aldrich, $\mathrm{M}=170.3 \mathrm{~g} \mathrm{~mol}^{-1}$ ).

- A 4,7,10-Trioxa-1,13-tridecanediamine hardener named here TTDA (CAS 4246-51-9 - ref 369519 supplied by Sigma Aldrich, $\left.\mathrm{M}=220.3 \mathrm{~g} \mathrm{~mol}^{-1}\right)$.

By combining those resins and hardeners, three systems were chosen: DGEBA/IPDA, DGEBA/TTDA, DGEBU/IPDA. These components were mixed in stoichiometric ratio and fully cured as checked by DSC from the total disappearance of exothermal signal and by FTIR from the total disappearance of epoxide peak at $914 \mathrm{~cm}^{-1}$. Curing enthalpies, curing cycles, final glass transition temperatures are listed in Table 1. In order to avoid the so-called Diffusion Limited Oxidation, films thinner than $100 \mu \mathrm{m}$ were made using a heating press (Gibrite Instruments).

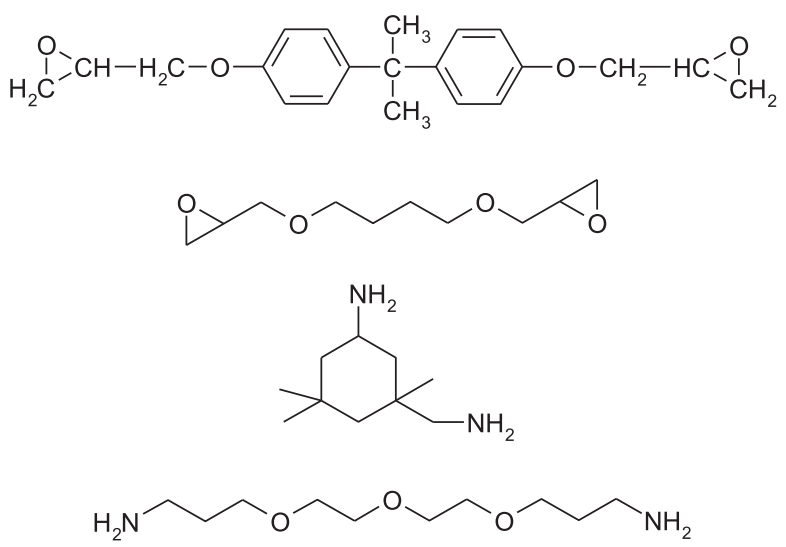

Fig. 1. Chemical structure of monomers DGEBA (a), DGEBU (b), IPDA (c), TTDA (d).

\subsection{Ageing}

Thermal ageing under atmospheric air was performed in ventilated ovens (calibrated at $\pm 3{ }^{\circ} \mathrm{C}$ ) at $110^{\circ} \mathrm{C}$ and $200^{\circ} \mathrm{C}$.

The influence of oxygen pressure was studied by performing ageing tests in autoclaves under 50 bars of pure oxygen at $110{ }^{\circ} \mathrm{C}$.

\subsection{Characterization}

\subsubsection{Oxidative products concentrations}

FTIR spectroscopy in transmission mode was performed on free standing films using a Frontier spectrophotometer (PerkinElmer) in the 550 to $4000 \mathrm{~cm}^{-1}$ wavenumber range by averaging 16 scans with a $4 \mathrm{~cm}^{-1}$ resolution. Spectra were interpreted using the Spectrum software (PerkinElmer) in order to determine the absorbance value from which the concentrations in main oxidation products (carbonyls and amides) was calculated according to the method defined elsewhere [20].

\subsubsection{Glass transition measurement}

Differential scanning calorimetry measurements were made with a DSC Q1000 (TA Instruments). Samples with mass ranging between 3 and $5 \mathrm{mg}$ sealed in aluminum pans were heated from $0{ }^{\circ} \mathrm{C}$ to $250{ }^{\circ} \mathrm{C}$ at a $10{ }^{\circ} \mathrm{C} \mathrm{min}^{-1}$ ramp under nitrogen flow $\left(50 \mathrm{ml} \mathrm{min}{ }^{-1}\right)$. Results were interpreted using TA Analysis software. DSC analyses were done to check the total cure of samples and to measure the value of the glass transition temperature of aged samples. $\mathrm{T}_{\mathrm{g}}$ values were measured during the second heating ramp (i.e. after having removed the thermal history of samples) at the inflexion point of the thermogram. Measurements were duplicated to control measurements reproducibility.

\section{Results}

The measurement of glass transition temperature of the networks is particularly interesting since it is related to the concentration and the flexibility of elastically active chains (those two quantities will be more precisely defined in the "Discussion" section). $\mathrm{T}_{\mathrm{g}}$ changes after ageing under air at 110 and $200{ }^{\circ} \mathrm{C}$ are given in Fig. 2. It can be observed that:

- DGEBA/IPDA displays a significant $\mathrm{T}_{\mathrm{g}}$ decrease under air, suggesting that oxidation induces an increase in the flexibility of segments and/or scissions of elastically active chains.

- DGEBA/TTDA displays a significant $T_{g}$ increase under air, suggesting that oxidation induces a decrease in the flexibility of segments and/or crosslinking.

- DGEBU/IPDA shows first a slight $T_{g}$ decrease but reactions responsible for an increase of $\mathrm{T}_{\mathrm{g}}$ seem to occur at high degradation level which means that they involve whether oxidation by products or sites with a low reactivity that are « activated » by a sort of co-oxidation process.

Table 1

Characteristics of the epoxy/amine networks.

\begin{tabular}{|c|c|c|c|c|c|}
\hline Epoxy/amine system & $\begin{array}{l}\text { Mass of hardener } \\
\text { for } 100 \mathrm{~g} \text { of epoxy }\end{array}$ & Crosslink exotherm & Exotherm onset temperature & Curing cycle & Glass transition temperature \\
\hline DGEBA/IPDA & $25 \mathrm{~g}$ & $563 \mathrm{~J} \mathrm{~g}^{-1}\left(0.47 \mathrm{~J} \mathrm{~mol}^{-1}\right)$ & $80^{\circ} \mathrm{C}$ & $\begin{array}{l}2 \mathrm{~h} 60{ }^{\circ} \mathrm{C} \text { in oven and post cure } \\
\text { of } 2 \mathrm{~h} \text { in vacuum at } 160^{\circ} \mathrm{C}\end{array}$ & $166^{\circ} \mathrm{C}$ \\
\hline DGEBU/IPDA & $42 \mathrm{~g}$ & $400 \mathrm{~J} \mathrm{~g}^{-1}\left(0.98 \mathrm{~J} \mathrm{~mol}^{-1}\right)$ & $85^{\circ} \mathrm{C}$ & $\begin{array}{l}2 \mathrm{~h} 85^{\circ} \mathrm{C} \text { in oven and post cure } \\
\text { of } 3 \mathrm{~h} \text { in vacuum at } 85^{\circ} \mathrm{C}\end{array}$ & $60{ }^{\circ} \mathrm{C}$ \\
\hline DGEBA/TTDA & $29 \mathrm{~g}$ & $395 \mathrm{~J} \mathrm{~g}^{-1}\left(0.44 \mathrm{~J} \mathrm{~mol}^{-1}\right)$ & $76{ }^{\circ} \mathrm{C}$ & $\begin{array}{l}1 \mathrm{~h} 60{ }^{\circ} \mathrm{C} \text { in oven and post cure } \\
\text { of } 3 \mathrm{~h} \text { in vacuum at } 80^{\circ} \mathrm{C}\end{array}$ & $69{ }^{\circ} \mathrm{C}$ \\
\hline
\end{tabular}




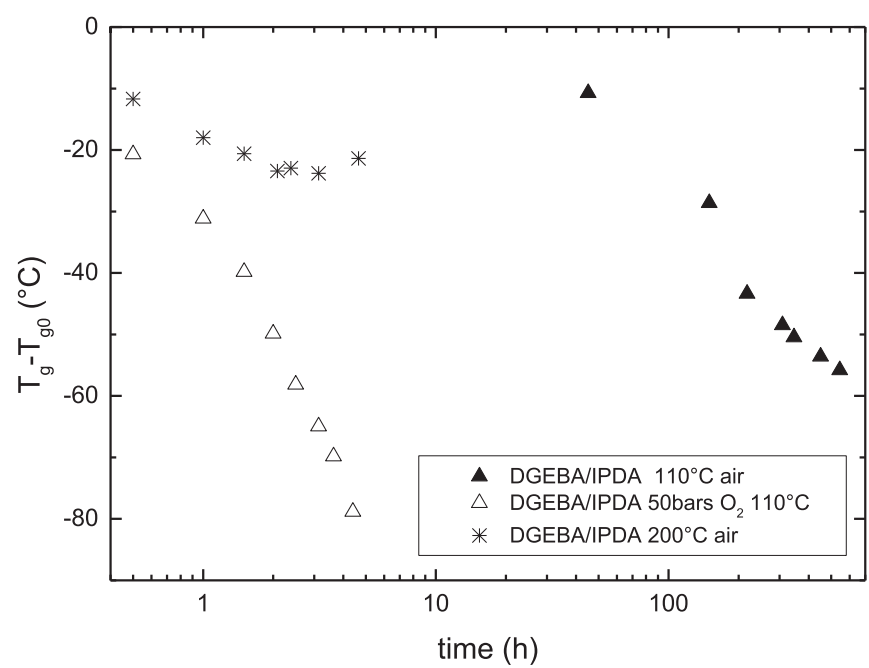

(a)

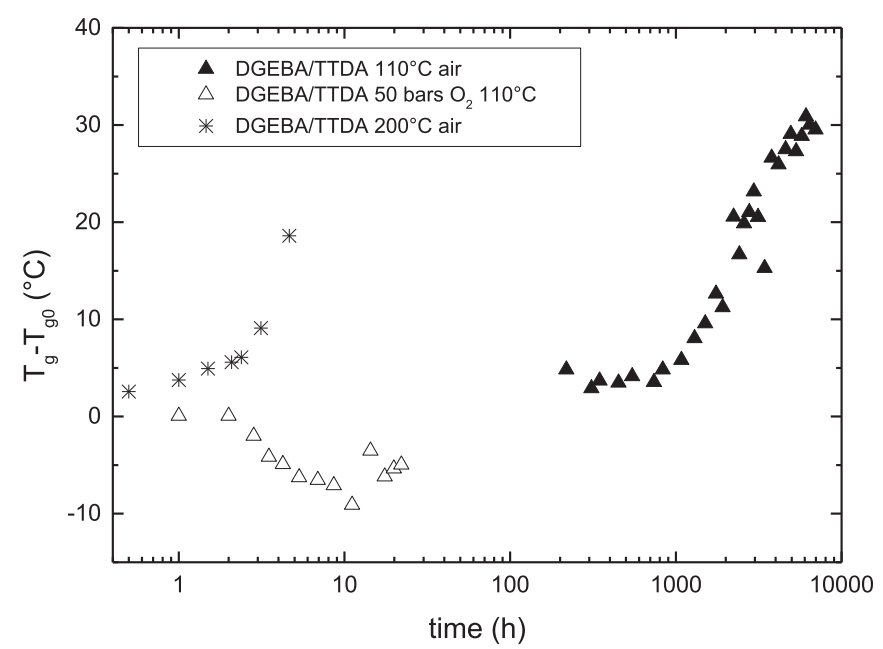

(b)

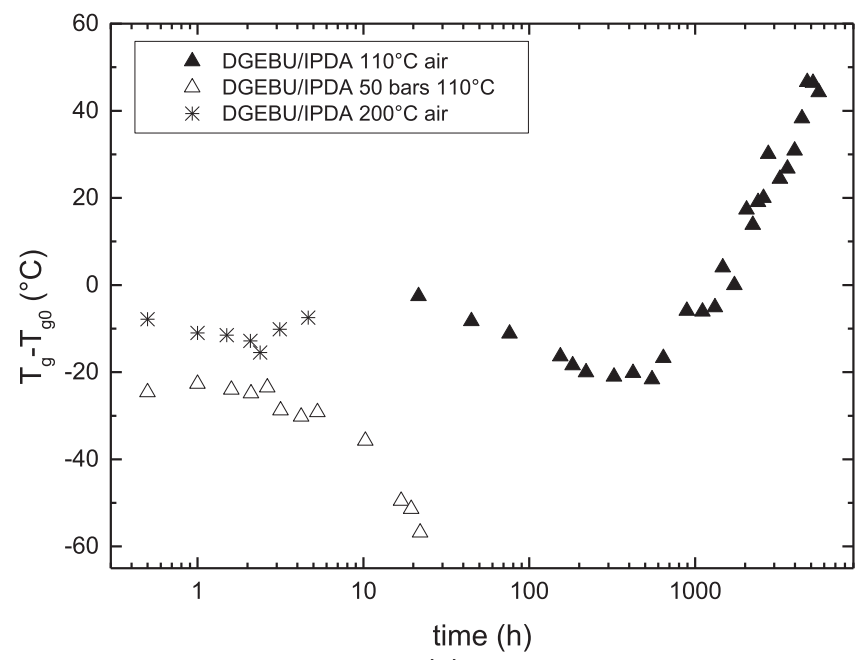

(c)

Fig. 2. $T_{g}$ changes versus time for DGEBA/IPDA (a), DGEBA/TTDA (b) and DGEBU/IPDA (c).

For DGEBA/TTDA and DGEBU/IPDA, results under 50 bars $\mathrm{O}_{2}$ indicate that reactions responsible for $\mathrm{T}_{\mathrm{g}}$ increase are suppressed. It suggests they originate from reactions between alkyl radicals being negligible under high oxygen pressures where terminations between $\mathrm{POO}^{\circ}$ predominate.

It appears also that reactions responsible for $T_{g}$ increase are slightly favored by temperature. On the assumption that $\mathrm{T}_{\mathrm{g}}$ increase comes from crosslinking, this would not be surprising since this later originates from bimomecular processes that are favored at higher temperatures where macromolecular mobility is enhanced.

Last, it appears that the common point of networks displaying $\mathrm{T}_{\mathrm{g}}$ increase (DGEBA/TTDA and DGEBU/IPDA) is the presence of methylenic sequences, which will be discussed in the following.

\section{Discussion}

The main aims of this section are:

- to investigate if $\mathrm{T}_{\mathrm{g}}$ changes come from chain scissions and crosslinking of elastically active chains and/or changes in the flexibility of these segments.

- to propose a mechanistic explanation consistent with the effect of oxygen pressure.

For that purpose, we will use the DiMarzio's theory [21] in which parameters are calculated using the additive group contributions proposed by Bellenger and Verdu [22].

\subsection{On the effect of structure on the initial $T_{g}$ values}

The glass transition of an ideal fully cured network is expected to obey DiMarzio's equation [21]:

$T_{g}=\frac{T_{g l}}{1-\left(K_{D M} F n\right)}$

Where:

- KDM is the DiMarzio's constant ca 2.91 for epoxy/amine trifunctional networks [22].

- $\mathrm{n}$ is the crosslink density $\left(\mathrm{mol} \mathrm{kg}^{-1}\right)$.

- $\mathrm{T}_{\mathrm{gl}}$ is the glass transition of the corresponding « virtual » linear polymer.

- $\mathrm{F}$ is the Flex parameter $\left(\mathrm{kg} \mathrm{mol}^{-1}\right)$ related to the molar mass per flexible bond.

$\mathrm{T}_{\mathrm{gl} 0}, \mathrm{~F}_{0}$ and $\mathrm{n}_{0}$ (the subscript 0 stands for virgin materials) can be assessed for unaged networks as presented in the following:

(1) $\mathrm{T}_{\mathrm{gl0}}$ can be predicted from the hypothesis of additive contribution of single components:

$T_{g l 0}=\frac{M_{U C R} *}{\sum M_{i} T_{g l i}^{-1}}$

Where:

- MUCR ${ }^{*}$ is the molar mass of a single repetitive unit (made of two prepolymer and a hardener unit but in which contribution of nitrogen atoms in crosslinks is suppressed).

- $\mathrm{M}_{\mathrm{i}} \cdot \mathrm{T}_{\mathrm{gi}}^{-1}$ is the contribution of each single component to $\mathrm{T}_{\mathrm{gl} 0}$. Values are given in Table 2. The contribution for IPD cycle (not given in Ref. [22]) was estimated as follows:

(1) First $\mathrm{T}_{\mathrm{gl}}$ of TTDA hardener was measured experimentally by DSC: $\mathrm{T}_{\mathrm{gl}}=238.2 \mathrm{~K}$. It is then possible to evaluate the contribution of the $\mathrm{NH}_{2}$ on $\mathrm{M}_{\mathrm{gl}}^{-1}$ :

$\mathrm{M}_{\mathrm{TTDA}} /\left(\mathrm{T}_{\mathrm{g}}\right)_{\mathrm{TTDA}}=3\left(\mathrm{M} / \mathrm{T}_{\mathrm{g}}\right)_{-\mathrm{O}-}+10\left(\mathrm{M} / \mathrm{T}_{\mathrm{g}}\right)_{-\mathrm{CH} 2-}+2\left(\mathrm{M} / \mathrm{T}_{\mathrm{g}}\right)_{-\mathrm{NH} 2}$ 
Table 2

Component values for $\mathrm{T}_{\mathrm{gl0}}$ calculation from Ref. [22] except for IPD (this work - see text).

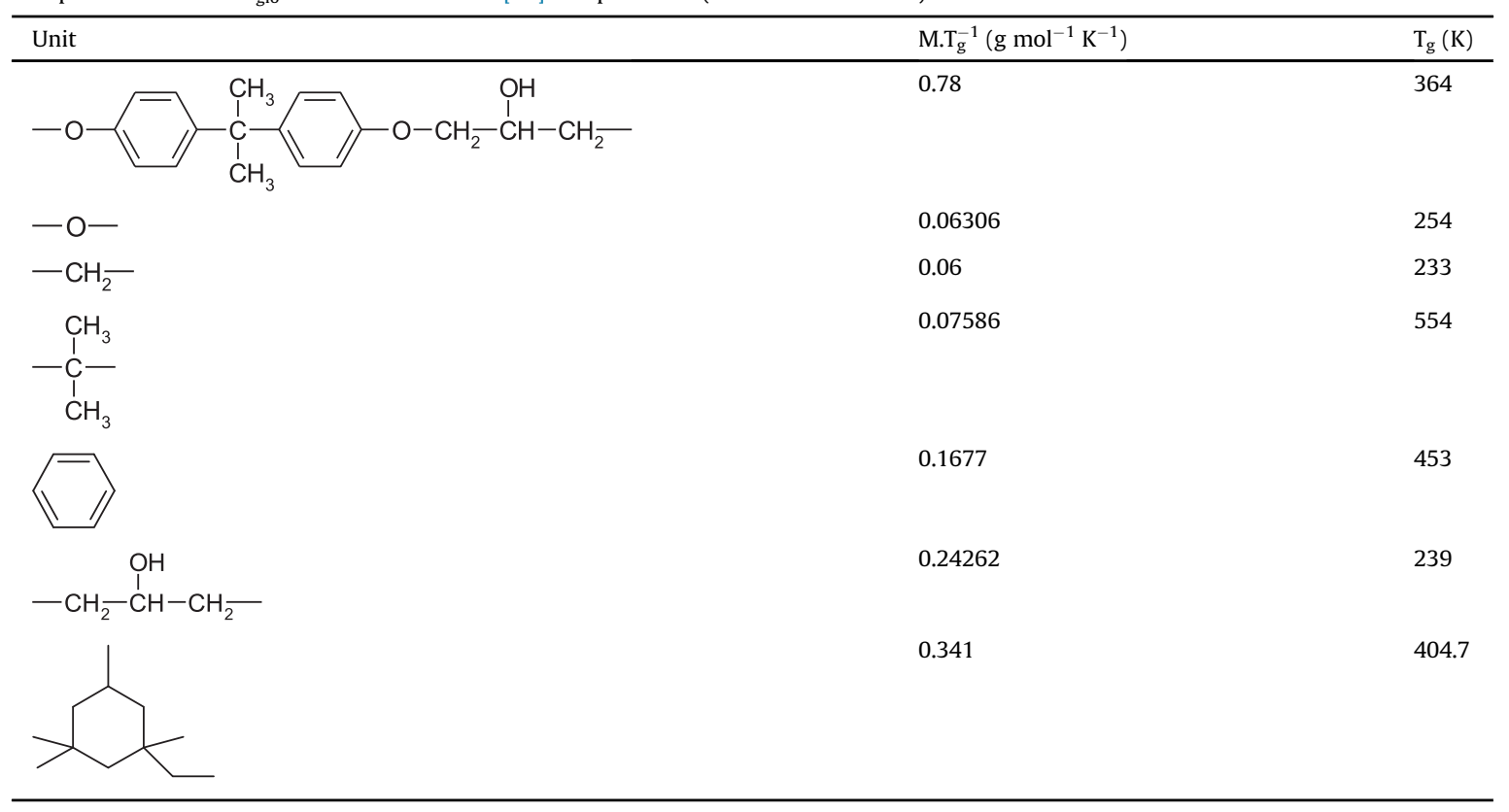

$$
\rightarrow\left(\mathrm{M} / \mathrm{T}_{\mathrm{g}}\right)_{\mathrm{NH} 2}=0.14677
$$

(2) Thanks to experimental value of $\mathrm{T}_{\mathrm{gl}}$ for IPDA $\left(\mathrm{T}_{\mathrm{gl}}=268 \mathrm{~K}\right)$ and contribution of $\mathrm{NH}_{2}$ from TTDA, the contribution of IPD can be determined:

$\mathrm{M}_{\mathrm{IPDA}} /\left(\mathrm{T}_{\mathrm{g}}\right)_{\mathrm{IPDA}}=\left(\mathrm{M} / \mathrm{T}_{\mathrm{g}}\right)_{\mathrm{IPD}}+2\left(\mathrm{M} / \mathrm{T}_{\mathrm{g}}\right)_{-\mathrm{NH} 2}=170 / 268$

$\rightarrow\left(\mathrm{M} / \mathrm{T}_{\mathrm{g}}\right)_{\mathrm{IPD}}=0.341$

The final $\mathrm{T}_{\mathrm{gl0}}$ values are given in Table 3.

(2) The Flex is defined as the ratio of molar mass of groups (without amine ends for hardener) per number of flexible bond $\gamma$ (see Table 4). The values $F_{0}$ for virgin networks were then calculated using:

$\mathrm{F}_{0}=\left(2 \times \mathrm{F}_{1}+\mathrm{F}_{2}\right) / 3$

$F_{1}$ and $F_{2}$ corresponding respectively to the prepolymer and the diamine hardener (TTD and IPD means that amine ends shall not to be taken into account in the calculation of flex for hardener segment) are given in Table 4 and $F_{0}$ values in Table 3.

(3) The crosslink density $\mathrm{n}_{0}$ was calculated as:

$\mathrm{n}_{0}=2 / \mathrm{M}_{\mathrm{UCR}}$

Experimental and calculated $\mathrm{T}_{\mathrm{g}}$ values are acceptably close (Table 3). It militates in favor of using DiMarzio's approach for investigating the origin of $\mathrm{T}_{\mathrm{g}}$ changes observed during thermal ageing in the following of this investigation.

\subsection{On the origins of glass transition changes during ageing}

The aim of this section is to quantitatively discuss on the origin of $\mathrm{T}_{\mathrm{g}}$ changes observed in Fig. 2.

As pointed out in the "Results" section for DGEBA/TTDA and DGEBU/IPDA, the reactions involving positive changes in $T_{g}$ occur under air and their influence decrease when elevating the oxygen pressure. The most satisfying explanation is that those reactions are terminations involving alkyl radicals such as $\mathrm{P}^{\circ}+\mathrm{P}^{\circ} \rightarrow$ inactive products [23]. The consequences on $\mathrm{T}_{\mathrm{g}}$ of such reactions will now be envisaged.

In DGEBA group, as assumed by Devanne et al. [24,25], the crosslinking between two radicals hold by 2-hydroxypropyl ether groups seems unlikely for two reasons:

- their steric hindrance,

- alkyl radicals react by $\beta$-scission (Scheme 1).

DGEBA group is thus expected to generate chain scissions rather

Table 4

Flex parameter calculation.

\begin{tabular}{llll}
\hline & $\mathrm{M}\left(\mathrm{g} \mathrm{mol}^{-1}\right)$ & $\gamma$ & $\mathrm{F}\left(\mathrm{g} \mathrm{mol}^{-1}\right)$ \\
\hline DGEBA & 342 & 12 & 28.5 \\
DGEBU & 204 & 13 & 15.7 \\
IPD & 138 & 5 & 27.6 \\
TTD & 188 & 14 & 13.4 \\
\hline
\end{tabular}

Table 3

Calculations using Eqs. (1)-(4) of $\mathrm{T}_{\mathrm{g} 0}$ for each epoxy/diamine system ( $\left.\mathrm{T}_{\mathrm{g} 0 \text { calc }}\right)$ and comparisons with experimental results ( $\mathrm{T}_{\mathrm{g} 0}$ exp).

\begin{tabular}{|c|c|c|c|c|c|c|c|}
\hline & $\sum \mathrm{M}_{\mathrm{i}} / \mathrm{T}_{\mathrm{gi}}\left(\mathrm{g} \mathrm{mol}^{-1} \mathrm{~K}^{-1}\right)$ & $\mathrm{T}_{\mathrm{gl0}}(\mathrm{K})$ & $\mathrm{F}_{0}\left(\mathrm{~g} \mathrm{~mol}^{-1}\right)$ & $\mathrm{M}_{\mathrm{UCR}}\left(\mathrm{g} \mathrm{mol}^{-1}\right)$ & $\mathrm{n}_{0}\left(\mathrm{~mol} \mathrm{~kg}^{-1}\right)$ & $\mathrm{T}_{\mathrm{g} 0} \exp (\mathrm{K})$ & $\mathrm{T}_{\mathrm{g} 0}$ calc $(\mathrm{K})$ \\
\hline DGEBA/TTDA & 2.834 & 307.6 & 23.5 & 900 & 2.35 & 343 & 363 \\
\hline DGEBA/IPDA & 2.386 & 344.5 & 28.2 & 850 & 2.22 & 439 & 427 \\
\hline DGEBU/IPDA & 2.044 & 264.2 & 19.7 & 572 & 3.5 & 333 & 330 \\
\hline
\end{tabular}




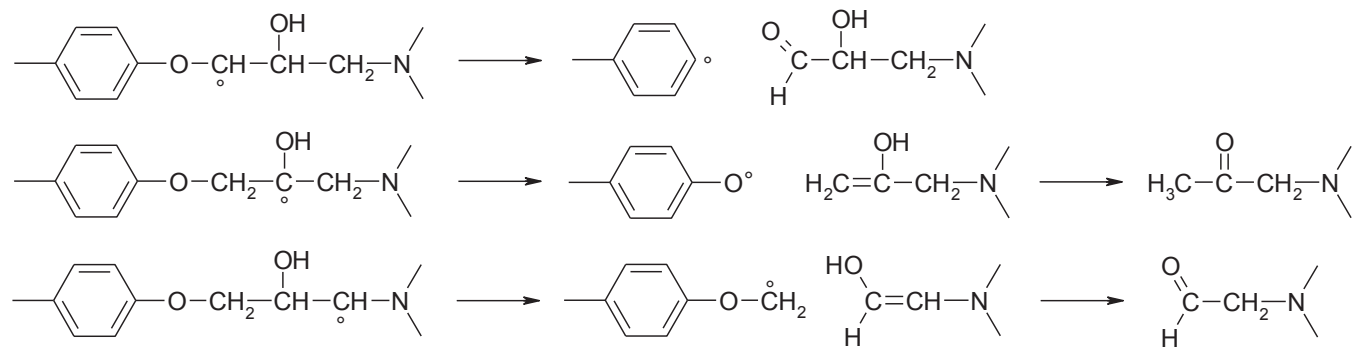

Scheme 1. Possible degradation pathway of alkyl radicals in DGEBA.<smiles>CN(C)CCCOCCOCCOCCCN(C)C</smiles><smiles>CN(C)CCCOCCOCCOCCCN(C)C</smiles>

Scheme 2. Possible intramolecular termination processes in TTDA group.<smiles>CN(C)CC(O)COCCCCOCC(O)CN(C)C</smiles><smiles>CN(C)CC(O)COCCCCOCC(O)CN(C)C</smiles>

Scheme 3. Possible intramolecular termination processes in DGEBU group.<smiles>CN(C)CCCOCCOCCOCCCN(C)C</smiles>

Scheme 4. Possible mechanisms for crosslinking involving TTDA group.

than crosslinking either under inert (Scheme 1) or oxygenated atmosphere (see later). It seems also difficult to envisage that two alkyl radicals hold by IPDA groups react to give a crosslink, here also due to the steric hindrance of substituted aliphatic rings [20]. The $\mathrm{T}_{\mathrm{g}}$ increase observed in DGEBA/TTDA and DGEBU/IPDA is hence expected to come from reactions occurring in TTDA or DGEBU units.

If radicals are created in $\alpha$ position of heteroatoms in TTDA or DGEBU (which is consistent with the nature of stable products observed in FTIR [20]), various intramolecular coupling processes (cyclization) lead to 5 or 6 members rings and a subsequent increase of $\mathrm{T}_{\mathrm{gl}}$ and Flex parameters (Schemes 2 and 3) or crosslinking between chains (Schemes 4 and 5).

According to Eq. (1), those reactions could be interpreted as changes in:

- concentration of elastically active chain i.e. crosslink density (n),

- flex parameter $(\mathrm{F})$,

- glass transition temperature of the linear polymer $\left(\mathrm{T}_{\mathrm{gl}}\right)$. 


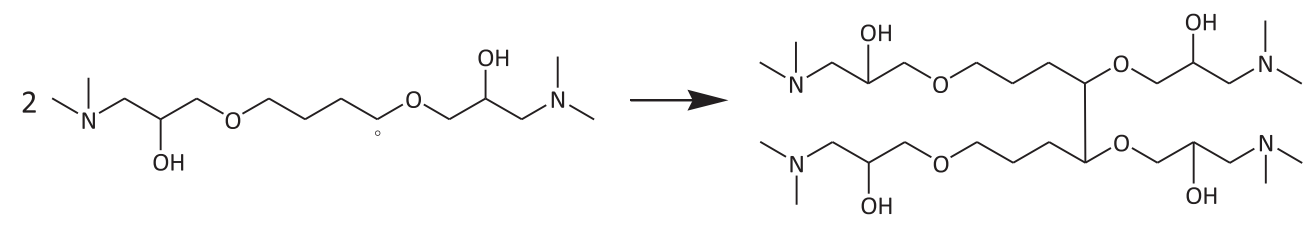

Scheme 5. Possible mechanisms for crosslinking involving DGEBU group.

Table 5

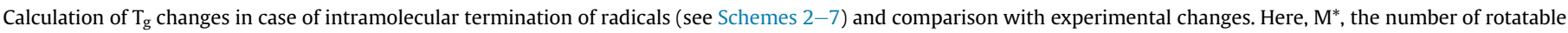
bonds $\gamma^{*}$ and flex $\mathrm{F}^{*}$ stands for the group being modified by oxidation, $\mathrm{F}_{\text {aged }}$ comes from Eq. (3) using $\mathrm{F}^{*}$ and $\Delta \mathrm{F}=\mathrm{F}_{\mathrm{aged}}-\mathrm{F}_{0}\left(\mathrm{~F}_{0}\right.$ given in Table 3 ).

\begin{tabular}{|c|c|c|c|c|c|c|}
\hline & $\mathrm{M}^{*}\left(\mathrm{~g} \mathrm{~mol}^{-1}\right)$ & $\gamma^{*}$ & $\mathrm{~F}^{*}\left(\mathrm{~g} \mathrm{~mol}^{-1}\right)$ & $\mathrm{F}_{\text {aged }}\left(\mathrm{g} \mathrm{mol}^{-1}\right)$ & $\Delta \mathrm{F}\left(\mathrm{g} \mathrm{mol}^{-1}\right)$ & $\Delta \mathrm{T}_{\mathrm{g}}$ with $\mathrm{T}_{\mathrm{gl0}}=307.6 \mathrm{~K}, \mathrm{n}_{0}=2.35 \mathrm{~mol} \mathrm{~kg}^{-1}$ \\
\hline TTDA $\rightarrow$ Ia & 186 & 10 & 18.6 & 25.2 & 1.7 & +14 K (+30 K experimentally observed) \\
\hline \multirow[t]{2}{*}{ TTDA $\rightarrow$ Ib } & 186 & 11 & 16.9 & 24.6 & 1.1 & +18 K (+30 K experimentally observed) \\
\hline & $\mathrm{M}^{*}\left(\mathrm{~g} \mathrm{~mol}^{-1}\right)$ & $\gamma^{*}$ & $\mathrm{~F}^{*}\left(\mathrm{~g} \mathrm{~mol}^{-1}\right)$ & $F_{\text {aged }}\left(\mathrm{g} \mathrm{mol}^{-1}\right)$ & $\Delta \mathrm{F}\left(\mathrm{g} \mathrm{mol}^{-1}\right)$ & $\Delta \mathrm{T}_{\mathrm{g}}$ with $\mathrm{T}_{\mathrm{gl0}}=264.2 \mathrm{~K}, \mathrm{n}_{0}=3.50 \mathrm{~mol} \mathrm{\textrm {kg } ^ { - 1 }}$ \\
\hline DGEBU $\rightarrow$ IIa & 182 & 9 & 20.2 & 22.7 & 3 & +27 K (+40 K experimentally observed) \\
\hline \multirow[t]{2}{*}{ DGEBU $\rightarrow$ IIb } & 182 & 10 & 18.2 & 21.3 & 1.6 & +24 K (+40 K experimentally observed) \\
\hline & $\mathrm{M}^{*}\left(\mathrm{~g} \mathrm{~mol}^{-1}\right)$ & $\gamma^{*}$ & $\mathrm{~F}^{*}\left(\mathrm{~g} \mathrm{~mol}^{-1}\right)$ & $F_{\text {aged }}\left(\mathrm{g} \mathrm{mol}^{-1}\right)$ & $\Delta \mathrm{F}\left(\mathrm{g} \mathrm{mol}^{-1}\right)$ & $\Delta \mathrm{T}_{\mathrm{g}}$ with $\mathrm{T}_{\mathrm{gl0}}=344.5 \mathrm{~K}, \mathrm{n}_{0}=2.22 \mathrm{~mol} \mathrm{~kg}^{-1}$ \\
\hline IPDA $\rightarrow$ III & 153 & 7 & 21.9 & 26.3 & -1.9 & $-16 \mathrm{~K}$ (-60 K experimentally observed) \\
\hline
\end{tabular}

We will now discuss if the products generated by alkyl radicals coupling are consistent with experimental $\mathrm{T}_{\mathrm{g}}$ increase using DiMarzio's equation as a "filter".

Reactions leading to a change in Flex parameter (e.g. intramolecular cyclization) are also expected to change the value of $\mathrm{T}_{\mathrm{gl}}$. It can thus be written:

$\frac{\partial T_{g}}{\partial F}=\frac{\partial T_{g l}}{\partial F} \times \frac{1}{1-K_{D M} \cdot F \cdot n_{0}}+\frac{T_{g l} \cdot K_{D M} \cdot n_{0}}{\left(1-K_{D M} \cdot F \cdot n_{0}\right)^{2}}$

Which can be rearranged using Eq. (1):

$\frac{\partial T_{g}}{\partial F}=\frac{T_{g}}{T_{g l}} \times\left[\frac{\partial T_{g l}}{\partial F}+T_{g 0} \cdot K_{D M} \cdot n_{0}\right]$

And finally:

$\Delta T_{g} \sim \frac{T_{g 0}}{T_{g l 0}} \times\left[\frac{\partial T_{g l}}{\partial F}+T_{g 0} \cdot K_{D M} \cdot n_{0}\right] \Delta F$

$\mathrm{T}_{\mathrm{g} 0}, \mathrm{~T}_{\mathrm{gl} 0}, \mathrm{n}_{0}$ standing for a virgin material and $\Delta \mathrm{F}$ being the increase in Flex coming from oxidation reactions.

It can be observed in the literature, within the family of virgin epoxy/diamine (Table 5 in Ref. [22]), that:

$\frac{\partial T_{g l}}{\partial F} \sim 4 \mathrm{Kmol} \mathrm{g}^{-1}$

By combining this last relationship and Eq. (7), it is now possible to assess $T_{g}$ changes as a function of Flex changes.

The $T_{g}$ values can be recalculated using Eq. (7) in the case of $100 \%$ conversion of TTDA or DGEBU groups into cyclic by-products presented in Schemes 2 and 3. It can be shown in Table 5 that the corresponding $T_{g}$ increase is lower than experimentally observed, meaning that even if those intramolecular processes are possible, they cannot quantitatively explain the experimental strong changes in $\mathrm{T}_{\mathrm{g}}$. The most possible reason is therefore the intermolecular reactions presented in Schemes 4 and 5.

The case of IPDA groups remains open. $T_{g}$ decrease in DGEBA/ IPDA and in DGEBU/IPDA might originate, at least in part, from scissions in hydroxypropyl ether groups in DGEBA and DGEBU (see Scheme 6) but the nature of degradation products of IPDA group is open. Two scenarii are possible.

- the first induces an opening of the ring, i.e. mainly a decrease in the Flex parameter (Scheme 7). According to Table 5, this process induces only a very low decrease in final $\mathrm{T}_{\mathrm{g}}$ value.

- the second (Scheme 8) involves the scission of an elastically active chain i.e. a decrease of the $n_{0}$ parameter in Eq. (1). It might thus be considered in complement of scissions of hydroxypropyl ether groups presented in Scheme 6.

Finally, one would have:

- for DGEBA/IPDA network: chain scissions in DGEBA and maybe IPDA groups.

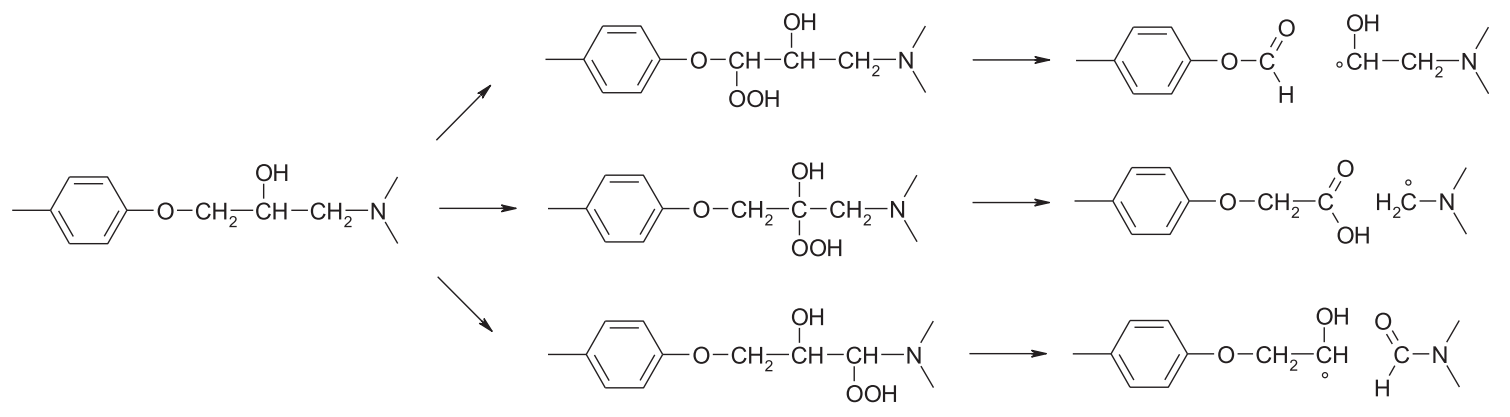

Scheme 6. Possible mechanism for chain scission in DGEBA group. 


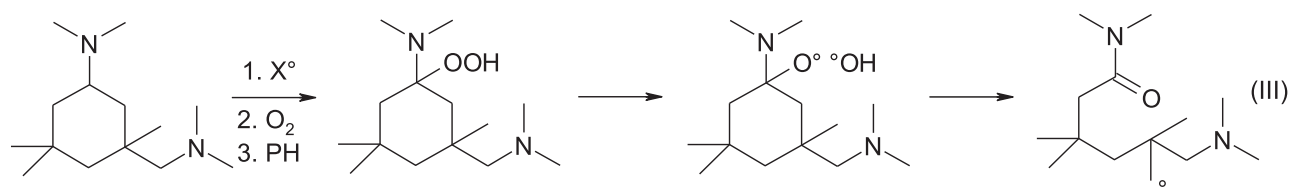

Scheme 7. Possible chain scission process in IPDA group.

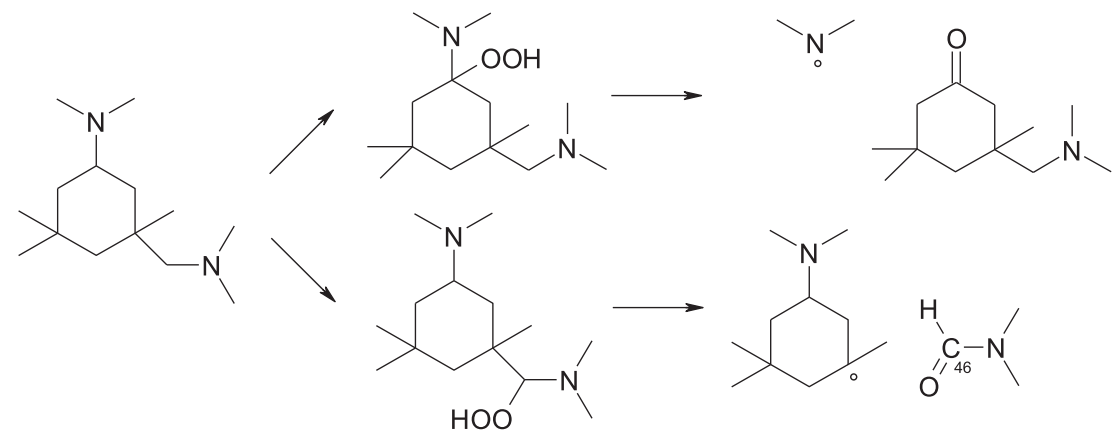

Scheme 8. Possible mechanism for chain scission in IPDA group.

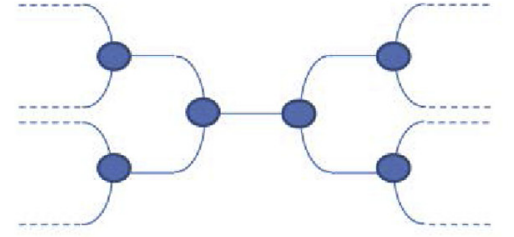

$\mathrm{EAC}=13$
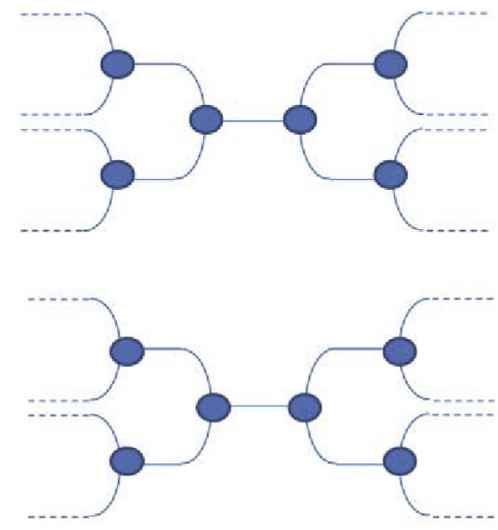

$E A C=26$
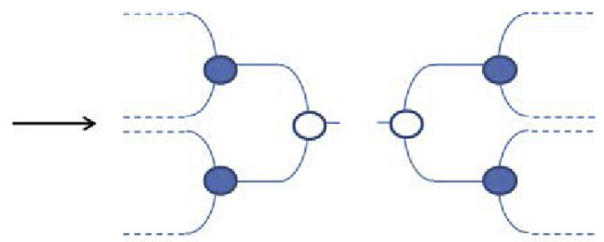

$E A C=10$

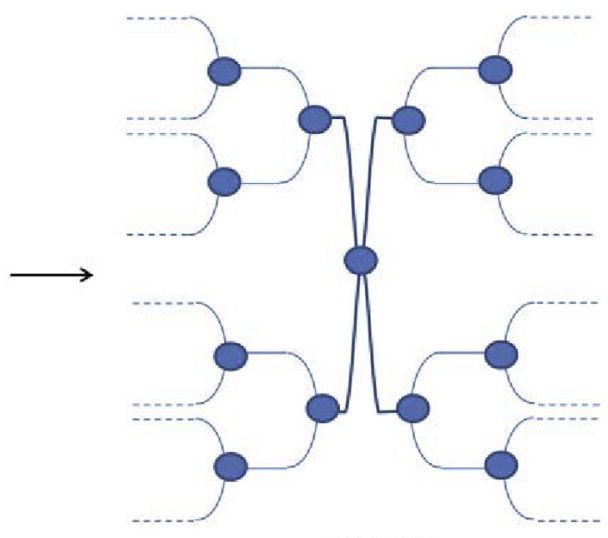

$\mathrm{EAC}=28$

Fig. 3. Effect of chain scission or crosslinking on the number of elastically active chains. Full dots represent crosslink nodes contributing to elasticity.

- for DGEBA/TTDA network: chain scissions in DGEBA counterbalanced by crosslinking in TTDA at least under air and progressively suppressed when increasing the oxygen concentration.

- for DGEBU/IPDA network: chain scissions in hydroxypropyl ether group of DGEBU and maybe IPDA counterbalanced by crosslinking in DGEBU at least under air and progressively suppressed when increasing the oxygen concentration.

The last step of this work is to quantify those phenomena using a modification of DiMarzio's equation as presented in the next paragraph.

\subsection{On the concentration in chain scissions and crosslinks}

According to which precedes, it is clear that oxidative ageing of epoxy resins leads to chain scissions or crosslinking modifying the crosslink density such as illustrated in Fig. 3.

Let us recall that an elastically active (EAC) chain has its two ends that are crosslink nodes connected to the network. It can thus be shown that, at low conversion degrees (where the network is close to ideality) [26]:

In the case of exclusive chain scissions:

$$
[\mathrm{EAC}]=[\mathrm{EAC}]_{0}-3 \mathrm{~S}
$$




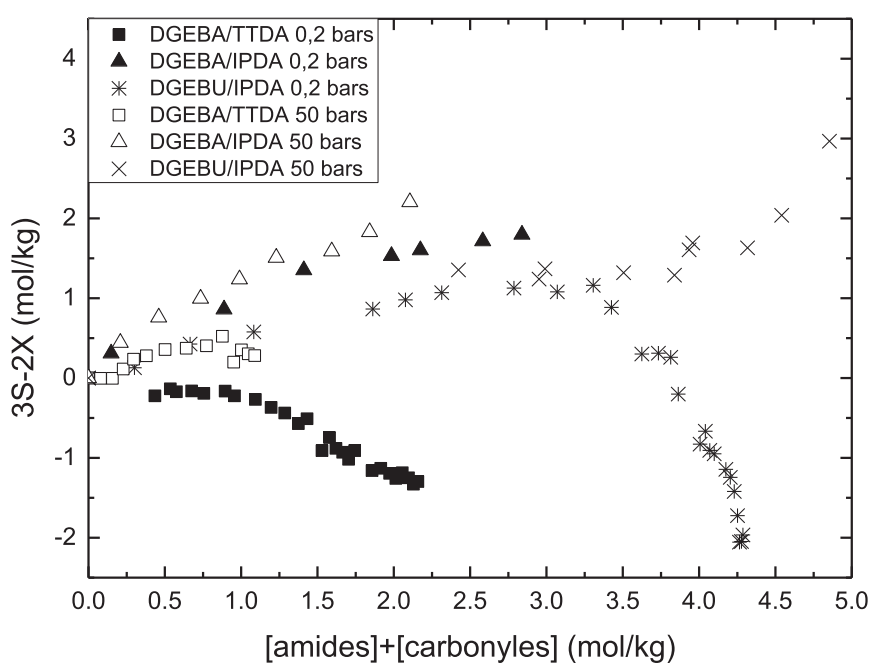

(a)

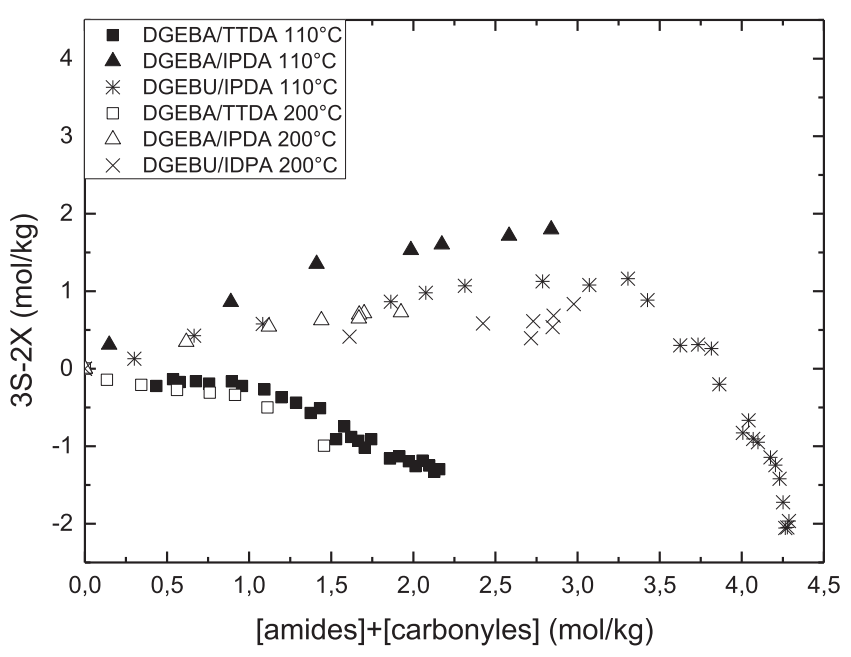

(b)

Fig. 4. Changes in $3 \mathrm{~S}-2 \mathrm{X}$ versus the concentration in stable oxidation products at $110{ }^{\circ} \mathrm{C}$ under air and under 50 bars $\mathrm{O}_{2}(\mathrm{a})$ and under air at 110 and $200{ }^{\circ} \mathrm{C}(\mathrm{b})$.

( $\mathrm{S}$ being the concentration in chain scission).

In the case of exclusive crosslink

$[\mathrm{EAC}]=[\mathrm{EAC}]_{0}+2 \mathrm{X}$

( $\mathrm{X}$ being concentration in crosslink).

And, in any case:
$[\mathrm{EAC}]=[\mathrm{EAC}]_{0}-3 \mathrm{~S}+2 \mathrm{X}$

For an ideal network of functionality f and crosslink density $n_{0}$, the concentration in elastically active chains (i.e. chains ended by two crosslink nodes connected to the network) is given by:

$[\mathrm{EAC}]_{0}=\mathrm{f} \times \mathrm{n}_{0} / 2$

The DiMarzio's equation can thus be modified to express the changes in $\mathrm{T}_{\mathrm{g}}$ in function of changes in network architecture:

$\left.\frac{1}{T_{g}(t)}-\frac{1}{T_{g 0}}\right) \times \frac{3 T g l}{2 K_{D M} F}=3 S-2 X$

The quantity $3 \mathrm{~S}$ - 2X was thus plotted versus the concentration in the main oxidation products as determined in Ref. [17] in Fig. 4, so as to discuss on the occurrence of chain scission and crosslinking at a given degradation level.

It was tried, for a given system, to estimate:

- the concentration chain scission per concentration oxidation products (amides + carbonyls) from measurements under elevated oxygen pressure where crosslinking are inhibited:

$A=3 S-2 X \sim 3 S$

i.e.

$\mathrm{S}=\mathrm{A} / 3$

where $\mathrm{A}$ is the slope of $3 \mathrm{~S}-2 \mathrm{X}$ vs [amides + carbonyls] under 50 bars $\mathrm{O}_{2}$

- and then the concentration in crosslinking from the measurements under air:

$\mathrm{X}=(\mathrm{A}-\mathrm{B}) / 2$

where B is the slope of $3 S-2 X$ vs [amides + carbonyls] under air. Results are given in Table 6 and call for following comments:

- It is easy to see that the crosslinking is favored with the concentration in methylenic structures participating to mechanisms such as proposed in Fig. 3.

- Since accelerated ageing tests often require higher temperatures and oxygen pressures [1-3], those observations confirm the difficulty to correlate results of accelerated tests with natural ageing ones. Kinetic modeling offers a solution provided that the reactions inducing crosslinking or chains scissions are ruled by rate constants obeying Arrhenius law, and that they are used in a kinetic model describing the relative occurrence of reactions with oxygen concentration [23].

Table 6

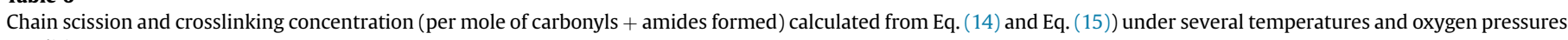
conditions.

\begin{tabular}{|c|c|c|c|c|c|c|c|}
\hline & \multicolumn{2}{|c|}{$110{ }^{\circ} \mathrm{C}-50$ bar $\mathrm{O}_{2}$} & \multicolumn{3}{|c|}{$110^{\circ} \mathrm{C}$ - air } & \multicolumn{2}{|c|}{$200{ }^{\circ} \mathrm{C}$ - air } \\
\hline & $3 S-2 X \sim 3 S$ & $\mathrm{~S}$ & $3 S-2 X$ & $\mathrm{X}$ & & $3 S-2 X$ & \\
\hline DGEBA/IPDA & 1.16 & 0.387 & 1.1 & 0.03 & & 0.58 & \\
\hline DGEBA/TTDA & 1.36 & 0.453 & $\begin{array}{l}-0.19 \\
-1.3\end{array}$ & $\begin{array}{l}0.78 \\
1.33\end{array}$ & $\begin{array}{l}{[\mathrm{CO}+\text { amides }]<1 \mathrm{~mol} \mathrm{~kg}^{-1}} \\
{[\mathrm{CO}+\text { amides }]>1 \mathrm{~mol} \mathrm{~kg}^{-1}}\end{array}$ & $\begin{array}{l}-0.26 \\
-1.3\end{array}$ & $\begin{array}{l}{[\mathrm{CO}+\text { amides }]<1 \mathrm{~mol} \mathrm{~kg}^{-1}} \\
{[\mathrm{CO}+\text { amides }]>1 \mathrm{~mol} \mathrm{~kg}^{-1}}\end{array}$ \\
\hline DGEBU/IPDA & 0.46 & 0.153 & $\begin{array}{l}0.6 \\
-5\end{array}$ & $\begin{array}{l}-0.07 \\
2.73\end{array}$ & $\begin{array}{l}{[\mathrm{CO}+\text { amides }]<2 \mathrm{~mol} \mathrm{~kg}^{-1}} \\
{[\mathrm{CO}+\text { amides }]>3 \mathrm{~mol} \mathrm{kg-1}}\end{array}$ & -4.58 & {$[\mathrm{CO}+$ amides $]<2 \mathrm{~mol} \mathrm{~kg}^{-1}$} \\
\hline
\end{tabular}




\section{Conclusions}

This paper presents a study of the thermo-oxidative ageing of three epoxy networks: DGEBA/IPDA, DGEBA/TTDA, DGEBU/IPDA, the two latter displaying some aliphatic linear sequences. Measurements of glass transition temperature (expressing the crosslink density) were derived to obtain the concentration in chain scissions and crosslinking. Those results indicate that DGEBA/TTDA and DGEBU/TTDA undergo a significant crosslinking possibly associated to the methylenic sequences. Those phenomena are partially suppressed by elevating the oxygen pressure. As a result, accelerated ageing tests using high oxygen pressures leads to complete different macromolecular modification for ageing under atmospheric conditions for a given oxidation state. Furthermore, the occurrence of crosslinking seems also possible for linear aliphatic epoxies and noticeable the new class of biobased epoxies [27,28]. In any case, it means that despite a certain commonality in changes observed by FTIR, the consequences of oxidation on backbone architecture differ for rigid or flexible epoxy resins. The consequences of either chain scissions and/or crosslinking on mechanical behavior of networks $[29,30]$ remains to be investigated in the case of epoxies.

\section{Acknowledgements}

ANRT (CIFRE $\mathrm{N}^{\circ}$ 2013/0356) is gratefully acknowledged for financial support.

\section{References}

[1] N. Rasoldier, X. Colin, J. Verdu, M. Bocquet, L. Olivier, L. Chocinski-Arnault, M.C. Lafarie-Frenot, Model systems for thermo-oxidised epoxy composite matrices, Compos. Part A Appl. Sci. Manuf. 39 (Issue 9) (September 2008) $1522-1529$.

[2] M. Pecora, Y. Pannier, M.-C. Lafarie-Frenot, M. Gigliotti, C. Guigon, Effect of thermo-oxidation on the failure properties of an epoxy resin, Polym. Test. 52 (July 2016) 209-217.

[3] M. Minervino, M. Gigliotti, M.C. Lafarie-Frenot, J.C. Grandidier, The effect of thermo-oxidation on the mechanical behaviour of polymer epoxy materials, Polym. Test. 32 (Issue 6) (September 2013) 1020-1028.

[4] C. Damian, E. Espuche, M. Escoubes, Influence of three ageing types (thermal oxidation, radiochemical and hydrolytic ageing) on the structure and gas transport properties of epoxy-amine networks, Polym. Degrad. Stab. 72 (Issue 3) (June 2001) 447-458.

[5] L. Olivier, N.Q. Ho, J.C. Grandidier, M.C. Lafarie-Frenot, Characterization by ultra-micro indentation of an oxidized epoxy polymer: correlation with the predictions of a kinetic model of oxidation, Polym. Degrad. Stab. 93 (Issue 2) (February 2008) 489-497.

[6] X. Buch, M.E.R. Shanahan, Thermal and thermo-oxidative ageing of an epoxy adhesive, Polym. Degrad. Stab. 68 (Issue 3, 11) (May 2000) 403-411.

[7] J. Decelle, N. Huet, V. Bellenger, Oxidation induced shrinkage for thermally aged epoxy networks, Polym. Degrad. Stab. 81 (Issue 2) (2003) 239-248.

[8] X. Colin, C. Marais, J. Verdu, Kinetic modelling and simulation of gravimetric curves: application to the oxidation of bismaleimide and epoxy resins, Polym.
Degrad. Stab. 78 (Issue 3) (2002) 545-553.

[9] M.C. Lafarie-Frenot, S. Rouquié, N.Q. Ho, V. Bellenger, Comparison of damage development in C/epoxy laminates during isothermal ageing or thermal cycling, Compos. Part A Appl. Sci. Manuf. 37 (Issue 4) (April 2006) 662-671.

[10] B.J. Anderson, Thermal stability of high temperature epoxy adhesives by thermogravimetric and adhesive strength measurements, Polym. Degrad. Stab. 96 (Issue 10) (October 2011) 1874-1881.

[11] B.J. Anderson, Thermal stability and lifetime estimates of a high temperature epoxy by Tg reduction, Polym. Degrad. Stab. 98 (Issue 11) (November 2013) 2375-2382.

[12] F. Daghia, F. Zhang, C. Cluzel, P. Ladevèze, Thermo-mechano-oxidative behavior at the ply's scale: the effect of oxidation on transverse cracking in carbon-epoxy composites, Compos. Struct. 134 (15) (December 2015) $602-612$.

[13] S. Terekhina, M. Mille, B. Fayolle, X. Colin, Oxidation induced changes in viscoelastic properties of a thermostable epoxy matrix, Polym. Sci. Ser. A 55 (Issue 10) (October 2013) 614-624.

[14] E.T. Denisov, I.B. Afanas'ev, Oxidation and Antioxidants in Organic Chemistry and Biology, CRC Press, March 29, 2005.

[15] J. Decelle, N. Huet, V. Bellenger, Oxidation induced shrinkage for thermally aged epoxy networks, Polym. Degrad. Stab. 81 (Issue 2) (2003) 239-248.

[16] M.C. Lafarie-Frenot, S. Rouquié, N.Q. Ho, V. Bellenger, Comparison of damage development in C/epoxy laminates during isothermal ageing or thermal cycling, Compos. Part A Appl. Sci. Manuf. 37 (Issue 4) (April 2006) 662-671.

[17] V. Bellenger, J. Verdu, Oxidative skeleton breaking in epoxy-amine networks, J. Appl. Polym. Sci. 30 (Issue 1) (1985) 363-374.

[18] C. Galant, B. Fayolle, M. Kuntz, J. Verdu, Thermal and radio-oxidation of epoxy coatings, Prog. Org. Coatings 69 (Issue 4) (December 2010) 322-329.

[19] Y. Zahra, F. Djouani, B. Fayolle, M. Kuntz, J. Verdu, Thermo-oxidative aging of epoxy coating systems, Prog. Org. Coatings 77 (Issue 2) (February 2014) $380-387$.

[20] E. Ernault, E. Richaud, B. Fayolle, Thermal oxidation of epoxies: influence of diamine hardener, Polym. Degrad. Stab. 134 (December 2016) 76-86.

[21] E.A. DiMarzio, On the second-order transition of a rubber, J. Res. Natl. Bureau Stand. Sect. A Phys. Chem. 68 (1964) 611-617.

[22] V. Bellenger, J. Verdu, E. Morel, Effect of structure on glass transition temperature of amine crosslinked epoxies, J. Polym. Sci. Part B Polym. Phys. 25 (Issue 6) (June 1987) 1219-1234.

[23] E. Richaud, F. Farcas, P. Bartoloméo, B. Fayolle, L. Audouin, J. Verdu, Effect of oxygen pressure on the oxidation kinetics of unstabilised polypropylene, Polym. Degrad. Stab. 91 (Issue 2) (February 2006) 398-405.

[24] T. Devanne, A. Bry, L. Audouin, J. Verdu, Radiochemical ageing of an amine cured epoxy network. Part I change of physical properties, Polymer 46 (Issue 1, 6) (January 2005) 229-236.

[25] T. Devanne, A. Bry, N. Raguin, M. Sebban, P. Palmas, L. Audouin, J. Verdu, Radiochemical ageing of an amine cured epoxy network. Part II: kinetic modelling, Polymer 46 (Issue 1, 6) (January 2005) 237-241.

[26] E. Richaud, P. Gilormini, M. Coquillat, J. Verdu, Crosslink density changes during the hydrolysis of tridimensional polyesters, Macromol. Theory Simulations 23 (Issue 5) (June 2014) 320-330.

[27] E. Darroman, N. Durand, B. Boutevin, S. Caillol, New cardanol/sucrose epoxy blends for biobased coatings, Prog. Org. Coatings 83 (June 2015) 47-54.

[28] R. Auvergne, S. Caillol, G. David, B. Boutevin, J.-P. Pascault, Biobased thermosetting epoxy: present and future, Chem. Rev. 114 (Issue 2) (2014) 1082-1115.

[29] J.E. Martin, D. Adolf, Constitutive equation for cure-induced stresses in a viscoelastic material, Macromolecules 23 (Issue 23, 1) (January 1990) 5014-5019.

[30] P.Y. Le Gac, D. Choqueuse, M. Paris, G. Recher, C. Zimmer, D. Melot, Durability of polydicyclopentadiene under high temperature, high pressure and seawater (offshore oil production conditions), Polym. Degrad. Stab. 98 (Issue 3) (March 2013) 809-817. 